Article

\title{
With a Little Help from My Friends: Peer Coaching for Refugee Adolescents and the Role of Social Media
}

\author{
Julia Kneer ${ }^{1, *}$, Anne K. van Eldik ${ }^{1}$, Jeroen Jansz ${ }^{1}$, Susanne Eischeid ${ }^{2}$ and Melek Usta ${ }^{3}$ \\ ${ }^{1}$ Erasmus School of History, Culture and Communication, Erasmus University Rotterdam, 3062 PA Rotterdam, \\ The Netherlands; E-Mails: kneer@eshcc.eur.nl (J.K.), vaneldik@eshcc.eur.nl (A.v.E.), jansz@eshcc.eur.nl (J.J.) \\ 2 Department of Differential Psychology, Duisburg-Essen University, 47057 Duisburg, Germany; \\ E-Mail: susanne.eischeid@stud.uni-due.de \\ 3 Peer2Peer, 2131 XE Hoofddorp, The Netherlands; E-Mail: m.usta@peer2peer-edu.nl \\ * Corresponding author
}

Submitted: 12 December 2018 | Accepted: 14 April 2019 | Published: 28 June 2019

\begin{abstract}
This intervention study investigated how much impact a specific peer-coaching (Peer2Peer) for refugee adolescents has on different factors of well-being for both sides: refugee adolescents (peers, $N=16$ ) and their local peer coaches (buddies, $N=16)$. Next to pre- and post-tests, four buddies reflected on the process via weekly media diaries. We found that higher peer-loneliness and lower self-esteem was reported for peers in the beginning but these differences disappeared. These results were confirmed by buddies' media diaries: language and communication barriers reduced and friendships between buddies and peers grew. Buddies also reported high feelings of responsibilities in their media diaries which led to worries about their peer, but also to pride due to peers' improvement. Online communication was used on an almost daily basis to stay in contact each other. Snapchat was found to influence emotional and affectionate support. In sum, Peer2Peer as a program showed positive effects for both sides. Future Peer2Peer programs should include trainings on social media as well, as most apps are able to be used independent of own language skills. Thus, social media can help to overcome language barriers and intensifies the feeling of being supported.
\end{abstract}

\section{Keywords}

adolescents; peer coaching; refugees; social inclusion; social media; well-being

Issue

This article is part of the issue "Refugee Crises Disclosed: Intersections between Media, Communication and Forced Migration Processes", edited Vasiliki Tsagkroni (Leiden University, The Netherlands) and Amanda Alencar (Erasmus University Rotterdam, The Netherlands).

(C) 2019 by the authors; licensee Cogitatio (Lisbon, Portugal). This article is licensed under a Creative Commons Attribution 4.0 International License (CC BY).

\section{Introduction}

Contemporary Europe is characterized by increasing cultural diversity. It not only results in issues with respect to communicating in different languages, but also in concerns that stem from different cultural values, norms, and behavioural standards. Many adolescents have to adapt to a new cultural environment including a new language, a new school, and new peers (Kammerl \& Kramer, 2016; Titzmann \& Jugert, 2015). Adolescents with and without migrant backgrounds have to find their way. Parents and teachers who are historically the experienced, wise ones are often overwhelmed themselves by cultural differences which may result in increased stereotype based behaviours (Glock, Kneer, \& Kovacs, 2013).

Independent of the changing world, adolescence is a time in life youth turns more and more away from parents and teachers and same-aged peers become more important (Wentzel, Russell, \& Baker, 2016). Youth that just arrived in a new culture and therefore have a strong 
need for orientation need peer orientation especially. If refugee adolescents receive such help from peers their well-being can increase. Same-aged peers that offer orientation might increase their own well-being since helping someone was found to impact self-status for adolescents (Schwartz, Meisenhelder, Ma, \& Reed, 2003).

Another contemporary development that is especially interesting for adolescents, targets new forms of communication such as social media. Communication via social media takes place without adult involvement and youth create relationships and new networks (Jansz, Slot, Tol, \& Verstraeten, 2015). Research on refugees and communication technologies found that social media helps with social inclusion in cases of forced migration (Díaz Andrade \& Doolin, 2017). Media usage as a new communication channel can impact the development of new friendships and therefore influence well-being as well. Handling social media including media based communication comes naturally for most adolescents and social media is now also a place for peers to meet (Kneer, Glock, Beskes, \& Bente, 2012; Kneer, Jacobs, \& Ferguson, 2019; Shifflet-Chila, Harold, Fitton, \& Ahmedani, 2016). Special social media apps such as Instagram and Snapchat are more or less language free since visual content is more emphasized (Kennisnet, 2017). Thus, language barriers might be reduced when communication happens via such social media and this form of communication can strengthen the development of friendships between local adolescents and refugee adolescents. With this intervention study we investigated the effects of a specific project that trains native Dutch adolescents to help refugee peers that just settled in the Netherlands and which role media communication plays. In other words:

RQ1: To what extent can peer coaching help to establish well-being for both sides: for native Dutch adolescents and refugee adolescents that just came to the Netherlands?

RQ2: To what extent does social media impact the change of well-being of Dutch and refugee adolescents?

RQ3: Does media usage impact well-being of Dutch and refugee adolescents that joined the project more than adolescents that did not join?

\section{Peer Coaching and Impact Adolescents}

\subsection{The Peer2Peer Approach}

The Dutch Peer2Peer institute is a social enterprise; its legal predecessor started in 2010. The method is now implemented at more than 55 secondary schools in the Netherlands. The Peer2Peer approach is a method of coaching aimed at making adolescents more successful in their school career. The idea is that coaching through peers helps to prevent frustration during the learning process, prevents possible isolation, and helps to develop 21st century skills such as self-reflection, working together and the integration in a new culture when children are from abroad. The peer coaches (buddies) are native Dutch adolescents and the trainees are refugee children that are new to the Netherlands (peers).

Buddies are trained in social and communicative skills. They learn to empathize with the situation of the peers they accompany and to explore the type of guidance they need. The buddy training takes place on three days and each of the sessions lasts approximately four hours. The training is conducted by at least one adult supervisor who has been educated by Peer2Peer and works as a teacher. After the initial training, each buddy meets with the adult supervisor at least once a month. When the need arises, buddies can consult their adult supervisor for mentoring in between times as well.

Buddies and peers meet during the last training day and are matched by gender, age, and neighbourhood areas. After this final training, buddies and their peers are supposed to meet up approximately once a week. Several activities are planned by the adult supervisors to support further relationship building between buddies and peers.

\subsection{Motivation and Well-Being of Native Dutch and Refugee Adolescents}

Research on youth showed a broad range of factors that influence individual well-being (e.g., Bradshaw, Keung, Rees, \& Goswami, 2011; Fattore, Mason, \& Watson, 2007; Federal Interagency Forum on Child and Family Statistics, 2015; Perreira \& Ornelas, 2011). Well-being is broadly defined as having positive feelings and control over what happens in one's life. Key aspects of well-being are self-esteem, positive relations with others, autonomy, environmental mastery, purpose in life, and personal growth (Ryff, 1989). We focused on social factors and educational motivation as Peer2Peer projects target specific social skills, relationships, and educational development.

It is important to see the reasons which are given to join such projects, hence, what motivates adolescents to become coaches for their peers and also what motivates refugee adolescents to learn more about the new culture in which they are living. One significant factor is the importance of education (e.g., Ager \& Strang, 2008), thus, the motivation to go to school. If motivation is highespecially for refugee adolescents - the motivation to integrate should rise, too, in order to gain from the new education system.

Another factor for joining such projects is social support. In the case of Dutch adolescents, high social support can induce the wish to help others (Cialdini, Brown, Lewis, Luce, \& Neuberg, 1997), and thus, increase the motivation to become a buddy. For refugee adolescents, the need for social support might be high due to their own families being either overwhelmed themselves with the new culture and situation, or sometimes even due to being on their own because they might not live with 
their families at all. Therefore, these factors (school motivation and social support) have to be evaluated in order to see if they differ between adolescents that joined or did not join such projects. We assume that:

H1: School motivation should be higher for refugee adolescents (peers) that joined the project than for refugee adolescents (control peers) that did not join the project.

H2: Social support should be higher for Dutch adolescents (buddies) that joined the project compared to Dutch adolescents (control buddies) that did not join the project.

The goal of the Peer2Peer approach is to help refugee adolescents to orient themselves in their new culture and to build new friendships (Peer2Peer, 2018). Thus, loneliness of refugee adolescents should be reduced after joining, and understanding the native Dutch culture aims to contribute to self-esteem and life satisfaction in general (Klemens \& Bikos, 2009; Ng \& Fisher, 2013). We expect that:

H3: Life satisfaction increases for refugee adolescents that joined the project.

H4: Self-esteem increases for refugee adolescents that joined the project.

H5: Peer loneliness decreases for refugee adolescents that joined the project.

Media usage as a communication channel can impact the development of new friendships and thus, influence well-being as well. While using social networks and media based communication comes naturally for most adolescents, such media is also a place for peers to meet (Jansz et al., 2015; Kneer et al., 2012, 2019; Shifflet-Chila et al., 2016). The use of digital communication showed promising results concerning social inclusion of refugee youth and therefore social media has high potential for social capital in Australia (Wilding, 2009). In addition, research on phone use showed that peer help via telephone lead to better integration and better understanding of the new culture: adult refugees in Australia reported that their mobile phones helped relieve loneliness and increase feelings of social support (Walker, Koh, Wollersheim, \& Walker, 2015). These studies focused on digital communication such as SMS and classical phone calls and peer to peer was arranged between persons who spoke the same language. Integration in a new culture might improve even more when including social media such as Instagram and Snapchat which are less language based (Kennisnet, 2017) and therefore can offer and support language-free communication when language barriers arise. Since we know that mobile communication plays a crucial role for social inclusion of refugees (Díaz Andrade \& Doolin, 2017), it is important to investigate if social media usage for the project group impacts the social factors of well-being more than for ado- lescents that are not part of the Peer2Peer project.

H6: Social media use has positive impact on social relatedness for the participants of the Peer2Peer project.

As this is an intervention study, we needed to investigate not only changes due to a Peer2Peer project but also focus on the process during the first weeks. For this purpose, we asked a number of participants from the buddies group to fill out a weekly media diary via WhatsApp, talking about their week with their peer. These media diaries gave insight into the experiences of the buddies and their perceptions of the experiences of the peers. While semi-structured through a number of questions, these media diaries offered the participants the opportunity to communicate freely without interruption, and to reflect upon the week at their own convenience/in their own time (Berg \& Düvel, 2012).

\section{Method}

\subsection{Sample}

For the Peer2Peer project, 16 adolescents from Dutch schools (buddies) and 16 adolescents from international schools (peers) were recruited. In order to have control groups, we also asked 16 adolescents each from the same schools that were not part of the Peer2Peer project to participate in our surveys (control buddies and control peers). Due to dropouts and illness on the data collection days, the final sample included 16 buddies, 14 peers (from Syria), 15 control buddies, and 12 control peers (most from Syria). All participants were aged 13-18 years $(M=14.09, S D=1.65)$ and $61.7 \%$ of the sample were female.

\subsection{Procedure Surveys and Media Diaries}

Before the first meeting between buddies and peers took place, the pre-test was conducted. Two Dutch native and one migrant research assistant introduced our study to the participants and helped with filling out the questionnaire in case there were questions. The order of questions is visible in Table 1 (including Cronbach's $\alpha$ s for both data collections).

\subsection{Procedure Media Diaries}

Four of the buddies were asked to answer five questions every week via WhatsApp and were handed mobile phones as well as sim cards for this. The questions were: 1 . Did you have contact with your peer this week?; 2. In case you did not have contact, what was the reason?; 3. How do you think your peer is doing?; 4. How are you doing as buddy? How do you feel in your role?; and 5. Did something special happen this week? If so, what happened? 
Table 1. Measurements for pre- and post-tests.

\begin{tabular}{|c|c|c|c|c|c|}
\hline Measurement & Items & Scale & $\alpha_{1}$ & $\alpha_{2}$ & Reference \\
\hline Demographics & gender, age, nationality & & & & \\
\hline Leisure activities & $\begin{array}{l}\text { team sports, individual sports, } \\
\text { time spent with friends, passive } \\
\text { activities (TV, books etc.), }\end{array}$ & $\begin{array}{l}1=\text { never; } \\
5=\text { always } \\
\text { cultural activities }\end{array}$ & & & \\
\hline Media usage & $\begin{array}{l}\text { online games, Facebook, } \\
\text { WhatsApp, Instagram, Snapchat }\end{array}$ & $\begin{array}{l}1=\text { never } \\
5=\text { always }\end{array}$ & & & \\
\hline School connectedness & 3 items & $\begin{array}{l}1=\text { never; } \\
6=\text { everyday }\end{array}$ & .51 & .61 & Lee (2009) \\
\hline School motivation & 8 items & $\begin{array}{l}1=\text { strongly disagree } \\
8=\text { strongly agree }\end{array}$ & .81 & .80 & Huebner (1994) \\
\hline $\begin{array}{l}\text { Peer norms for school } \\
\text { performance }\end{array}$ & 3 items & $\begin{array}{l}1=\text { not important } \\
5=\text { very important }\end{array}$ & .81 & .86 & Sokatch (2006) \\
\hline Self-esteem & 10 items (one dismissed) & $\begin{array}{l}1=\text { totally disagree; } \\
4=\text { totally agree }\end{array}$ & .75 & .79 & Rosenberg (1965) \\
\hline Life satisfaction & 7 items & $\begin{array}{l}1=\text { totally disagree, } \\
6=\text { strongly agree }\end{array}$ & .74 & .82 & Huebner (1994) \\
\hline Emotional support & 4 items & $\begin{array}{l}1=\text { strongly disagree } \\
6=\text { strongly agree }\end{array}$ & .87 & .90 & $\begin{array}{l}\text { Sherbourne and } \\
\text { Stewart (1991) }\end{array}$ \\
\hline Social distraction & 3 items & $\begin{array}{l}1=\text { strongly disagree } \\
6=\text { strongly agree }\end{array}$ & .77 & .75 & $\begin{array}{l}\text { Sherbourne and } \\
\text { Stewart (1991) }\end{array}$ \\
\hline Affectionate support & 3 items & $\begin{array}{l}1=\text { strongly disagree } \\
6=\text { strongly agree }\end{array}$ & .87 & .86 & $\begin{array}{l}\text { Sherbourne and } \\
\text { Stewart (1991) }\end{array}$ \\
\hline Social anxiety & 9 items & $\begin{array}{l}1=\text { never true; } \\
4=\text { always true }\end{array}$ & .65 & .67 & Crick and Ladd (1993) \\
\hline Peer loneliness & 16 items & $1=$ never $; 4=$ often & .90 & .91 & Crick and Ladd (1993) \\
\hline
\end{tabular}

\subsection{Analyses of the Media Diaries}

A thematic analysis approach was used to analyse the media diaries (Braun \& Clarke, 2006). After the process of transcribing and familiarizing with the data, 100 initial topics were found, thus, 100 codes were established. In searching for themes, a number of 5 themes, with 3 to 6 subthemes each, were found, after which these were limited to a number of 5 themes, which then were further defined and specified.

\section{Results: Pre- and Post-Tests}

Paired sample t-tests were run for each group to analyse if differences after 14 weeks of the projects occurred. Neither buddies nor peers nor control peers showed any significant differences between pre- and post-tests. Only control buddies showed a higher school connectedness at the second data collection $\left(M_{\text {pre }}=4.08, S D_{\text {pre }}=0.68\right.$; $\left.M_{\text {post }}=4.50, S D_{\text {post }}=0.72\right), t(15)=3.87, p=.002$.

\subsection{Comparisons between All Groups for Pre- and Post-Tests}

All measurements were compared for buddies vs. peers, buddies vs. control buddies and peers vs. control peers. $t$-tests for independent samples for pre- and post-tests were used.

\subsubsection{Buddies vs. Peers}

For the pre-tests we found that buddies compared to peers showed higher self-esteem $\left(M_{b}=2.88, S D_{b}=0.51\right.$; $\left.M_{p}=2.34, S D_{p}=0.69\right), t(27)=2.41, p=.023$, less peer loneliness $\left(M_{b}=1.32, S D_{b}=0.46 ; M_{p}=1.92\right.$, $\left.S D_{p}=0.62\right), t(27)=3.03, p=.005$, higher emotional support $\left(M_{b}=4.50, S D_{b}=0.45 ; M_{p}=3.60, S D_{p}=0.58\right)$, $t(27)=4.73, p<.001$ and higher social distraction $\left(M_{b}=4.35, S D_{b}=0.86 ; M_{p}=3.41, S D_{p}=0.85\right)$, $t(27)=2.94, p=.007$. Compared to buddies, peers scored only higher on school motivation $\left(M_{b}=4.06\right.$, $\left.S D_{b}=0.21 ; M_{p}=5.14, S D_{p}=0.21\right), t(27)=3.63, p<.001$.

For the post-tests we found significant differences between buddies and peers again for emotional sup- 
port $\left(M_{b}=4.31, S D_{b}=0.15 ; M_{p}=3.52, S D_{p}=0.82\right)$, $t(28)=3.06, p=.004$, and social distraction, $\left(M_{b}=4.38\right.$, $\left.S D_{b}=0.14 ; M_{p}=3.60, S D_{p}=0.94\right), t(28)=2.80, p=.009$. This time, affectionate support was found to be higher for buddies as well $\left(M_{b}=4.36, S D_{b}=0.56 ; M_{p}=3.29\right.$, $\left.S D_{p}=1.09\right), t(28)=3.47, p=.002$. Peers scored again higher concerning school motivation $\left(M_{b}=4.08\right.$, $\left.S D_{b}=0.79 ; M_{p}=4.90, S D_{p}=0.75\right), t(28)=2.93, p=.007$. Interestingly, buddies showed less life satisfaction than peers $\left(M_{b}=3.74, S D_{b}=0.38 ; M_{p}=4.32, S D_{p}=0.62\right)$, $t(28)=3.10, p=.004$.

\subsubsection{Buddies vs. Control Buddies}

Analyses of pre surveys showed that buddies scored significant higher than control buddies on school connectedness $\left(M_{b}=4.62, S D_{b}=0.80 ; M_{c b}=4.08, S D_{c b}=0.68\right)$, $t(30)=2.06, p=.048$ and on emotional support $\left(M_{b}=4.50, S D_{b}=0.45 ; M_{c b}=3.83, S D_{c b}=0.76\right)$, $t(30)=3.04, p=.006$. No further comparisons were found to be significant for the pre survey. For posttests only life satisfaction revealed significant differences showing lower scores for buddies than for control buddies $\left(M_{b}=3.74, S D_{b}=0.38 ; M_{c b}=4.04, S D_{c b}=0.39\right)$, $t(30)=2.20, p=.036$.

\subsubsection{Peers vs. Control Peers}

For the pre-tests we found that peers showed higher school motivation than control peers $\left(M_{p}=5.14\right.$, $\left.S D_{p}=0.21 ; M_{c p}=4.38, S D_{c p}=0.55\right), t(30)=3.13$, $p=.004$. Self-esteem was found to be lower for peers than for control peers $\left(M_{p}=2.34, S D_{p}=0.69 ; M_{c p}=2.77\right.$, $\left.S D_{c p}=0.27\right), t(30)=2.30, p=.029$, and peers scored also higher on peer loneliness $\left(M_{p}=1.92, S D_{p}=0.62\right.$; $\left.M_{c p}=1.36, S D_{c p}=0.39\right), t(30)=3.02, p=.005$.

No significant differences were found for any measurement for the post-test.

\subsection{Influence of Free Time Activities and Media Usage on Social Well-Being}

We analysed if social activities and social media usage can predict well-being. We included time spent with friends as predictor because this free time activity was reported most. Snapchat was included as it is known to be on the rise especially for younger generations (Anderson
\& Jiang, 2018; Kennisnet, 2017; Smith \& Anderson, 2018). Snapchat uses less language and is more about sharing pictures, etc., so language barriers should not play a major role.

Multiple linear regression analyses for emotional support, social distraction, affectionate support, and peer loneliness as dependent variables and time spent with friends and Snapchat usage as predictors were calculated for the project group (buddies and peers) and the control group (control buddies and control peers) for the second survey round.

Time spent with friends had no predictive value for any of the social well-being criteria, however, Snapchat usage was a positive significant predictor for emotional and affectionate support (See Table 2 for all $\beta$ s and $F$-values). No regression model or predictor was found to be significant for the control group.

\section{Results Media Diaries}

\subsection{Hanging Out Online and Offline}

The first theme to be discussed is the space where communication took place-where the peer and buddy essentially hung out. Here one can find an important distinction between online and offline (face-to-face).

Online or other mediated communication refers to all forms of non-face-to-face communication that happened between the peer and buddy that included a medium. This was done by the use of social media (e.g., Whatsapp, Instagramm, Snapchat). What is interesting is that although online communication was not always explicitly mentioned as hanging out, it did not make this contact any less important. When the two did not meet up face-to-face it was often mentioned that social media was used to keep in contact:

I did not have [face-to-face] contact with my peer (except via WhatsApp). (Buddy \#1)

We did not have contact outside of WhatsApp. (Buddy \#4)

Social media, therefore, played a central role in keeping in contact and also initiating contact, micro-coordination, and even hanging out.

Offline contact entailed meeting up face-to-face, either in a public or private space, and either with two or

Table 2. Time spent with friends and Snapchat usage as predictors for social well-being variables for the Peer2Peer group.

\begin{tabular}{lcccc}
\hline & $F(2.27)$ & $R^{2}$ & Friends & \multicolumn{2}{c}{ Snapchat } \\
Criteria & & & $\beta$ & $\beta$ \\
\hline Emotional support & $12.15^{* * *}$ & $.48^{* * *}$ & .07 & $.65^{* * *}$ \\
Social distraction & $4.48^{*}$ & $.27^{*}$ & .30 & .31 \\
Affectionate support & $6.41^{* *}$ & $.33^{* *}$ & .32 & $.36^{*}$ \\
Peer loneliness & $4.13^{*}$ & $.24^{*}$ & -.26 & -.33 \\
\hline
\end{tabular}

Notes: ${ }^{*} \mathrm{p}<.05,{ }^{* *} \mathrm{p}<.01, \mathrm{p}<.001$. 
more people, doing different activities. The distinction between meeting in private or in public showed quite large differences: out of the 32 instances of meeting up, 20 were in a public location and 8 were in a private place, such as the buddy's home (6 times) or the peer's home ( 2 times). The four other meetings were not specified.

This result is in line with findings that showed that hanging around online can enhance the development of a friendship (Buote, Wood, \& Pratt, 2009) and that online contact is seen as similar to offline communication (Reich, Subrahmanyam, \& Espinoza, 2012). Social support offline can even be established via online friendship (Trepte, Reinecke, \& Juechems, 2012).

\section{Communication and Conflicts}

The introduction of culturally different people in the lives of both the buddies and the peers-both from a different perspective-was also found as a central theme in the media diaries, as this was a source of confusion and sometimes conflict on different levels. Buddies expressed that they tried hard to help their peers, but that in different ways language or miscommunication obstructed this. As a participant explained:

I think [he has] improved in asking stuff, although I have the feeling that the language barrier is bigger than I anticipated. I had to teach him how to work at a different station [at work], and I had to explain 500 times before he did it right. He said he understood, but this wasn't the case. (Buddy \#3)

Most buddies indicated that the communication skills of the peers improved with time, which also increased the ease with which relationships between the buddies and the peers were established.

Not all interactions remained conflict-free. While it did not occur frequently, the media diaries showed a specific situation where true conflict arose. A peer was invited to a social event that included the buddy's friends and food. Without communicating a reason, the peer quickly left before the end of the event, leaving the buddy in distress. The buddy explained:

He left rather quickly and I didn't feel like he was having a good time. I felt quite bad about him having a bad time, but I didn't really know what I should have done differently or what I should do about it now. (Buddy \#4)

This conflict was first reported to have caused some worries on the buddies side. Later on this buddy reported that there was a lack of communication that caused the conflict, however, it was resolved quickly afterwards. Solving the conflict did indeed lead to a better understanding and contributed to intensifying their relationship which is in line with findings that show that conflict resolution matures friendships (Nelson \& Aboud, 1985; Vera, Shin, Montgomery, Mildner, \& Speight, 2004)

\section{Development of Friendship}

Overall the media diaries showed development of friendships. Participants sometimes communicated at first that they felt a little awkward or unsure of what to do, and noted many ups and downs along the way, but often they reported an increase in feelings of friendship. This links to the findings for communication and conflicts; solving conflicts helped to develop friendships and/or showed that friendships were already established (Nelson \& Aboud, 1985). Over time, buddies mention this as well in their media diaries: Two examples illustrate:

It's become less awkward between us, so communication has become easier and the atmosphere has improved. (Buddy \#2)

I have the feeling that we [have become] really good friends. (Buddy \#1)

We have already built a good relationship. (Buddy \#2)

These expressions show that the buddies are aware that relationships with their peers improve, which in most cases resulted in the development of friendship. This requires an idea of mutual feelings, indicating that they feel this is the case for their peer as well. In addition, all buddies report that the language skills of peers improved which led to a better understanding and also supported the development of friendships. As a buddy illustrates: "I think he is doing better and better, also on a social level. Communicating seems to become easier for him" (Buddy \#3).

\section{Peer's Well-Being}

Changes in peer's well-being were central to the media diaries. Generally, the buddies reported that the peer felt good, only in small number of instances, they interpreted their peer's mood as moderate or bad. One important topic was peers' need for help and their responses to it. They needed help for a variety of reasons, among which were school, work, and language. Buddies explained that there were different ways for the peers to deal with their need for help:

I think he is doing better, he is better at answering than before, and he takes initiative to ask more questions. (Buddy \#3)

I asked her if I could help her with something, but [she said] I didn't have to. (Buddy \#2)

My peer is doing well. I think my role as a buddy is becoming easier, because my peer is making it increasingly clear what they want to do and what I can help them with. (Buddy \#2)

Buddies sometimes initiated the support themselves. One buddy arranged a job for their peer, which was accepted. The positive shift in which peers ask for help more often over time relates to an increased self- 
efficiency of peers which was perceived by the buddies and is a well-known key element of well-being (Perreira \& Ornelas, 2011; Vera et al., 2004). The increased wellbeing of peers also positively influenced the well-being of their buddies. Clearer communication, increased selfefficiency, and the development of friendships were reflected on the buddies' side.

\section{Buddy's Experience}

Buddies rarely reported on feeling bad or having big issues. Many reported feeling good about their peer's improvements and the establishment of friendship. In those cases, the buddy expressed a sense of pride in his or her diary.

This pride seems to partly come from their sense of responsibility. Throughout the media diaries, buddies reported a strong sense of responsibility which caused both positive and negative feelings. Whenever their peer succeeded or friendship grew, they felt proud and happy. However, this sense of responsibility also seemed a burden in some cases. Some felt guilty for not being able to meet up often enough, others wanted to offer help but did not know how or were declined. A buddy explained: "I have the feeling that I should do more for [the relationship with the peer], take the lead a little more" (Buddy \#3).

Some reported that they felt like they had to take constant initiative, but wanted their peer to do so, too. The media diaries showed a quite a strong drive among most of the buddies to help their peers, but these responsibilities sometimes turned out to be a great burden to the young participants. Overcoming these issues seemed to strengthen pride even more. As one participant argued:

I think my peer is doing well, because she keeps saying that she feels like meeting up. I, as a buddy, feel good, [and] because she says she wants to meet up, I look forward to it more and more as well. (Buddy \#2)

Again, the increased self-efficiency of peers is reported and leads to a stronger relationship which in turn has impact on the buddies' well-being; especially if this process is experienced with a sense of pride (Schwartz \& Sendor, 1999).

\section{General Discussion}

The findings from the pre- and post-tests on motivational factors and well-being show: 1 ) as assumed (H1) peers have higher motivation than control peers for education which explains their interest in joining the Peer2Peer project. This is in line with research that argues that educational motivation plays an important role in adolescents' integration into a new culture (e.g., Ager \& Strang, 2008). Good education is only possible if school systems including language adaption are understood. Projects like Peer2Peer can help with integration which again leads to a better education. This means that the wish for motivation for education influences the motivation to integrate into the new culture. Motivation for education is therefore crucial for integration motivation. 2) Buddies indeed feel high social support $(\mathrm{H} 2)$ which can be interpreted as their main motivation to join and "give to others" (Cialdini et al., 1997). This result from the surveys is supported by buddies' media diaries. They not only report strong feelings of responsibility towards their peers, but they also act on this and try to support them socially. In sum with the finding that peers show high motivation for education, the reason for adolescents to join such integration projects is twofold: for peers it's the wish for a good education, and for buddies it's the wish to give back to others. 3) In contrast to our assumptions (H3) life satisfaction was found to be lower for buddies during the post-test. It is important to note, that life satisfaction was quite high for all groups, thus, this is not a reason to worry that Peer2Peer has negative impact on buddies. The analyses of the media diaries reveal that feeling responsible for their peer seems to overwhelm buddies from time to time. Buddies know that they can meet and talk about issues with their adult supervisors, however, want to react faster to their peers. This can influence life satisfaction (Proctor, Linley, \& Maltby, 2009). 4) Somewhat in line with the argument that self-esteem should rise for peers (H4), we found that peers did show lower self-esteem in the beginning but did not differ from buddies and control peers after 14 weeks of the project. Thus, self-esteem for peers increased. Still, we don't know why self-esteem was lower for peers in the beginning. Low self-esteem could be seen as further motivation to join a project like Peer2Peer to feel better on that well-being concept. Future studies should address the question if low self-esteem increases the wish for integration. 5) Similar to self-esteem and partly in line with our assumptions ( $\mathrm{H} 5)$, peer loneliness for peers was first higher but these differences disappeared later. The media diaries support that peers have fewer problems with communication and contact overall became easier. This explains why self-esteem levels become similar and why peer loneliness is no longer higher compared to other groups. Buddies report about the development of their friendships, how conflicts were solved, and their perspective of their peer's well-being. Buddies describe a good development of their relationship to the peers. In addition, conflicts that arose helped each other understand the other's culture and personality. Peer loneliness in the beginning was alleviated by the development of a good relationship with the buddies. These findings are in line with research on adult refugees and the importance of social support for successful migration (Bierwiaczonek \& Waldzus, 2016; Schweitzer, Melville, Steel, \& Lacherez, 2006; Simich \& Mawani, 2003) and especially backing the argument that social support from locals is of high significance for integration (Oppedal, 2011; Podsiadlowski, Vauclair, \& Spiess, 2013). Thus, programs like Peer2Peer that are supporting the develop- 
ment of such social networks are of great importance for successful migration.

Besides, the changes due to the Peer2Peer project we analysed the influence mobile communication has on different aspects of well-being. The idea was based on studies that highlight the importance of mobile use for refugees in general (Alencar, Kondova, \& Ribbens, 2018) and especially on social inclusion (Díaz Andrade \& Doolin, 2017) as well as on the argument that social media can be used as "adult-free" zone (Jansz et al., 2015). We found that Snapchat could explain emotional and affectionate support-but only for the Peer2Peer project group-which is in line with our assumptions (H6). Snapchat influences the emotional side of support but only for the children that were included in the project. Snapchat is quite popular among children while usage amongst adults is relatively low (Anderson \& Jiang, 2018; Kennisnet, 2017; Smith \& Anderson, 2018). This is supported by the reports of buddies: Hanging around online via specific social media such as Snapchat was reported to be high, especially if there was little time to meet face to face. The use of social media supported the development of friendship.

This study has several limitations. First and most importantly, the sample size was considerably small. Due to the time intensive training of buddies (and peers) it was not possible to include more children in the project and in the accompanying study. Results-especially for the quantitative pre- and post-tests-have to be treated carefully. Still, findings of these surveys are supported by the weekly media diaries which speaks for the positive influence of Peer2Peer projects. Another criticism can be that we only asked buddies for their perspective during the process but did not involve peers in the media diaries. In future studies, it is advisable to include peers and their perception of the progress of the peer coaching as well. Due to the given length of the surveys we did not include other interesting scales such as cultural openness and empowerment. Cultural openness might be one of the main motivations to join such projects and should even increase due to joining and also have impact on well-being. One factor that can be considered to be important in terms of well-being is empowerment. Not only peers but also buddies should be affected with regard to empowerment by joining such projects and this should be included in future intervention studies.

In sum, our study showed that the Peer2Peer intervention had positive impact for both Dutch and refugee children. Not only peers but also buddies gain positive insights and develop soft skills that are important for present day societies that will become more and more culturally diverse. Even if buddies felt overwhelmed from time to time, they did enjoy their role and were able to help their peers when needed. Important to note is that media usage is a supportive factor-especially social media that are used for fun and communication that goes beyond language or does not even need language at all (such as Snapchat). One suggestion for future mi- gration programs is to include trainings in media literacy for the participants and for supervisors. Research on training programs for teachers in Nairobi, Toronto, and Vancouver indicated that group chats between teachers and participants as well as single communication could solve problems such as fights and lead to higher learning outcomes in actual classrooms (Dahya et al., 2019). Applying these results to programs that involve supervisors and participants with and without migrant background, social media can improve the communication between all parties. Participants can learn how to overcome language barriers by using specific social media, while supervisors might be able to help sooner by being available online in addition to personal meetings. This can reduce the feelings of being overwhelmed with responsibility on the buddies' side. Communication happens quickly nowadays, and adolescents use it for the establishment of friendships. Thus, including social media usage in the Peer2Peer training and process can: 1) improve its already existing positive effects on the development of friendships between buddy and peer; and 2) help buddies and their adult supervisors to stay in touch and solve upcoming issues for buddies faster.

\section{Acknowledgments}

We thank Peer2Peer and the accompanying schools in Nijmegen for joining this study and Vodafone Ziggo for sponsoring the four mobile phones and contracts for the project's media diaries. Special thanks goes to Kari Leonard for all discussions on the primary ideas, her insight, and last but not least her help concerning the English language.

\section{Conflict of Interests}

The authors declare no conflict of interests.

\section{References}

Ager, A., \& Strang, A. (2008). Understanding integration: A conceptual framework. Journal of Refugee Studies, 21(2), 166-191. http://doi.org/10.1038/tpj.2011.14

Alencar, A., Kondova, K., \& Ribbens, W. (2018). The smartphone as a lifeline: An exploration of refugees' use of mobile communication technologies during their flight. Media, Culture and Society, 2018. http://doi. org/10.1177/0163443718813486

Anderson, M., \& Jiang, J. (2018). Teens, social media \& technology 2018. Pew Research Center. Retrieved from https://www.pewinternet.org/2018/05/31/ teens-social-media-technology-2018

Berg, M., \& Düvel, C. (2012). Qualitative media diaries: An instrument for doing research from a mobile media ethnographic perspective. Interactions: Studies in Communication \& Culture, 3(1), 71-89. http://doi. org/10.1386/iscc.3.1.71

Bierwiaczonek, K., \& Waldzus, S. (2016). Socio-cultural 
factors as antecedents of cross-cultural adaptation in expatriates, international students, and migrants: A review. Journal of Cross-Cultural Psychology, 47(6), 767-817. http://doi.org/10.1177/ 0022022116644526

Bradshaw, J., Keung, A., Rees, G., \& Goswami, H. (2011). Children's subjective well-being: International comparative perspectives. Children and Youth Services Review, 33(4), 548-556. http://doi.org/10.1016/j. childyouth.2010.05.010

Braun, V., \& Clarke, V. (2006). Using thematic analysis in psychology. Qualitative Research in Psychology, 3(2), 77-101. http://doi.org/10.1191/ 1478088706qp063oa

Buote, V. M., Wood, E., \& Pratt, M. (2009). Exploring similarities and differences between online and offline friendships: The role of attachment style. Computers in Human Behavior, 25(2), 560-567. http://doi.org/ 10.1016/j.chb.2008.12.022

Cialdini, R. B., Brown, S. L., Lewis, B. P., Luce, C., \& Neuberg, S. L. (1997). Reinterpreting the empathyaltruism relationship: When one into one equals oneness. Journal of Personality and Social Psychology, 73(3), 481-494. http://doi.org/10.1037/0022-3514. 73.3 .481

Crick, N. R., \& Ladd, G. W. (1993). Children's perception of their peer experiences: Attributions, loneliness, social anxiety, and social avoidance. Developmental Psychologypmental Psychology, 29(2), 244-254.

Dahya, N., Dryden-Peterson, S., Douhaibi, D., Arvisais, O., Dahya, N., Dryden-Peterson, S., . . . Arvisais, O. (2019). Social support networks, instant messaging, and gender equity in refugee education. Information, Communication \& Society, 22(6), 774-790. http:// doi.org/10.1080/1369118X.2019.1575447

Díaz Andrade, A., \& Doolin, B. (2017). Information and communication technology and the social inclusion of refugees. MIS Quarterly, 40(2), 405-416. http:// doi.org/10.25300/misq/2016/40.2.06

Fattore, T., Mason, J., \& Watson, E. (2007). Children's conceptualisation(s) of their well-being. Social Indicators Research, 80(1), 5-29. http://doi.org/10.1007/ s11205-006-9019-9

Federal Interagency Forum on Child and Family Statistics. (2015). America's children: Key national indicators of well-being, 2015. Washington, DC: U.S. Government Printing Office. Retrieved from https://www. childstats.gov/pdf/ac2015/ac_15.pdf

Glock, S., Kneer, J., \& Kovacs, C. (2013). Preservice teachers' implicit attitudes toward students with and without immigration background: A pilot study. Studies in Educational Evaluation, 39(4), 204-210. http://doi. org/10.1016/j.stueduc.2013.09.003

Huebner, E. S. (1994). Preliminary development and validation of a multidimensional life satisfaction scale for children. Psychological Assessment, 6(2), 149-158.

Jansz, J., Slot, M., Tol, S., \& Verstraeten, R. (2015). Everyday creativity: Consumption, participation, produc- tion, and communication by teenagers in the Netherlands. Journal of Children and Media, 9(2), 143-159. http://doi.org/10.1080/17482798.2015.1015433tle

Kammerl, R., \& Kramer, M. (2016). The changing media environment and its impact on socialization processes in families. Studies in Communication Sciences, 16(1), 21-27. http://doi.org/10.1016/j.scoms.2016. 04.004

Kennisnet. (2017). Monitor Jeugd en Media 2017 [Monitor youth and media]. Kennisnet. Retrieved from https://www.kennisnet.nl/publicaties/monitorjeugd-en-media

Klemens, M. J., \& Bikos, L. H. (2009). Psychological wellbeing and sociocultural adaptation in college-aged, repatriated, missionary kids. Mental Health, Religion and Culture, 12(7), 721-733. http://doi.org/10.1080/ 13674670903032629

Kneer, J., Glock, S., Beskes, S., \& Bente, G. (2012). Are digital games perceived as fun or danger? Supporting and suppressing different game-related concepts. Cyberpsychology, Behavior, and Social Networking, 15(11), 604-609. http://doi.org/10.1089/ cyber.2012.0171

Kneer, J., Jacobs, R., \& Ferguson, C. J. (2019). You could have just asked: The perception of motivations to play violent video games. Studies in Media and Communication, 6(2), 1-11. http://doi.org/10. 11114/smc.v6i2.3389

Lee, S. J. (2009). Online communication and adolescent social ties: Who benefits more from internet use? Journal of Computer, 14(3), 509-531. http://doi.org/ 10.1111/j.1083-6101.2009.01451.x

Nelson, J., \& Aboud, F. E. (1985). The resolution of social conflict between friends. Child Development, 56(4), 1009-1017. http://doi.org/10.2307/1130112

Ng, E. C. W., \& Fisher, A. T. (2013). Understanding wellbeing in multi-levels: A review. Health, Culture and Society, 5(1), 308-323. http://doi.org/10.5195/HCS. 2013.142

Oppedal, B. (2011). The role of social support in the association between perceived discrimination and mental health among young Immigrants in Norway. International Journal of Developmental Science, 5(1/2), 85-99. http://doi.org/10.3233/DEV-2011-11076

Peer2Peer. (2018). Peer2Peer. Retrieved from https:// peer2peer-edu.nl

Perreira, K. M., \& Ornelas, I. J. (2011). The physical and psychological well-being of immigrant children. Future of Children, 21(1), 195-218. http://doi.org/10. 1353/foc.2011.0002

Podsiadlowski, A., Vauclair, C., \& Spiess, E. (2013). Social support on international assignments: The relevance of socioemotional support from locals relevance of socioemotional support from locals. International Journal of Psychology, 48(4), 563-573. http:// doi.org/10.1080/00207594.2012.669042

Proctor, C. L., Linley, P. A., \& Maltby, J. (2009). Youth life satisfaction: A review of the literature. Journal 
of Happiness Studies, 10(5), 583-630. http://doi.org/ 10.1007/s10902-008-9110-9

Reich, S. M., Subrahmanyam, K., \& Espinoza, G. (2012). Friending, IMing, and hanging out face-to-face: Overlap in adolescents' online and offline social networks. Developmental Psychology, 48(2), 356-368. http:// doi.org/10.1037/a0026980

Rosenberg, M. (1965). Rosenberg self-esteem scale (RSE). In J. Ciarrochi \& L. Bilich (Eds.), Acceptance and commitment therapy: Measures package (p. 61). Wollongong: School of Psychology, University of Wollongong.

Ryff, C. D. (1989). Happiness is everything, or is it? Explorations on the meaning of psychological well-being. Journal of Personality and Social Psychology, 57(6), 1069-1081. http://doi.org/10.1037/0022-3514.57.6. 1069

Schwartz, C. E., Meisenhelder, J. B., Ma, Y., \& Reed, G. (2003). Altruistic social interest behaviors are associated with better mental health. Psychosomatic Medicine, 65(5), 778-785. http://doi.org/10.1097/ 01.PSY.0000079378.39062.D4

Schwartz, C. E., \& Sendor, R. M. (1999). Helping others helps oneself: Response shift effects in peer support. Social Science and Medicine, 48(11), 1563-1575. http://doi.org/10.1016/S0277-9536(99)00049-0

Schweitzer, R., Melville, F., Steel, Z. \& Lacherez, P. (2006). Trauma, post-migration living difficulties, and social support as predictors of psychological adjustment in resettled Sudanese refugees. Australia and New Zealand Journal of Psychiatry, 40(2), 179-187.

Sherbourne, C. D., \& Stewart, A. L. (1991). The MOS social support survey. Social Science Medicine, 32(6), 705-714.

Shifflet-Chila, E. D., Harold, R. D., Fitton, V. A., \& Ahmedani, B. K. (2016). Adolescent and family development: Autonomy and identity in the digital age. Children and Youth Services Review, 70, 364-368. http://doi.org/10.1016/j.childyouth.2016.10.005

Simich, L., \& Mawani, F. N. (2003). Social support and the significance of shared experience in refugee migration and resettlement. Western Journal of Nursing
Research, 25(7), 872-891. http://doi.org/10.1177/ 0193945903256705

Smith, A., \& Anderson, M. (2018). Social media use in 2018. Pew Research Center. Retrieved from http://www.pewinternet.org/2018/03/01/socialmedia-use-in-2018

Sokatch, A. (2006). Peer influences on the college-going decisions of low urban youth. Education and Urban Society, 39(1), 128-146. http://doi.org/10.1177/ 0013124506291783

Titzmann, P. F., \& Jugert, P. (2015). Acculturation in context: The moderating effects of immigrant and native peer orientations on the acculturation experiences of immigrants. Journal of Youth and Adolescence, 44(11), 2079-2094. http://doi.org/10.1007/ s10964-015-0314-0

Trepte, S., Reinecke, L., \& Juechems, K. (2012). The social side of gaming: How playing online computer games creates online and offline social support. Computers in Human Behavior, 28(3), 832-839. http://doi.org/ 10.1016/j.chb.2011.12.003

Vera, E. M., Shin, R. Q., Montgomery, G. P., Mildner, C., \& Speight, S. L. (2004). Conflict resolution styles, self-efficacy, self-control, and future orientation of urban adolescents. Professional School Counseling, 8(1), 73-80.

Walker, R., Koh, L., Wollersheim, D., \& Walker, R. (2015). Social connectedness and mobile phone use among refugee women in Australia. Health and Social Care in the Community, 23(3), 325-336. http://doi.org/10. 1111/hsc.12155

Wentzel, K. R., Russell, S., \& Baker, S. (2016). Emotional support and expectations from parents, teachers, and peers predict adolescent competence at school. Journal of Educational Psychology, 108(2), 242-255. http://doi.org/10.1037/edu0000049

Wilding, R. (2009). Refugee youth, social inclusion, and ICTs: Can good intentions go bad? Journal of Information, Communication and Ethics in Society, 7(2/3), 159-174. http://doi.org/10.1108/ 14779960910955873

\section{About the Authors}

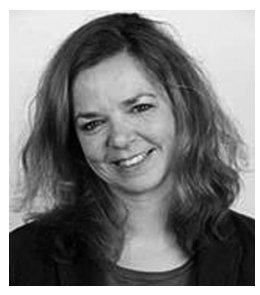

Julia Kneer is currently working as Assistant Professor at the Department of Media and Communication at the Erasmus University Rotterdam. She reached her habilitation and venia legendi at the University of Cologne in 2013 and her PhD in Soical Psychology in 2006. Her research focuses on digital games, perception of media use, general media effects, well-being, media and migration, and social psychology. Please visit juliakneer.com for an overview over her projects and publications.

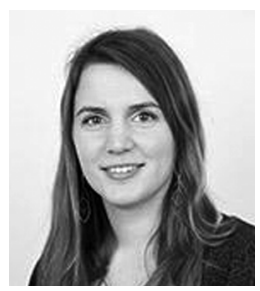

Anne K. van Eldik, MA, MSc is a PhD candidate at the Erasmus Research Centre for Media, Communication and Culture (ERMeCC) at the Erasmus University Rotterdam. Her current research interests include media engagement, the role of social media in identity construction among adolescents, and creative media use in an urban context, as well as the role of social media in the (re)building of social capital. 


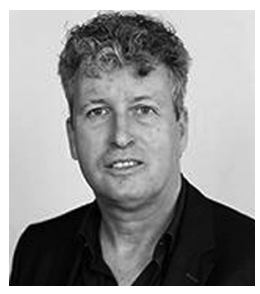

Jeroen Jansz, PhD holds the Chair of Communication and Media in the Department of Media \& Communication at Erasmus University Rotterdam and is a member of the Erasmus Research Centre for Media, Communication, and Culture. His research is about the reception of social media. Jansz has (co-) authored about 45 international scientific publications and 3 international books, and about 30 scientific publications and 4 books in Dutch. For an overview see http://jeroenjansz.nl/

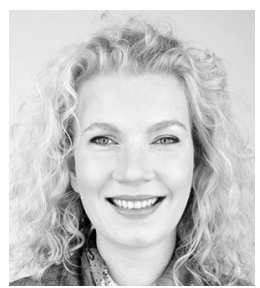

Susanne Eischeid studied Psychology at the University of Cologne with a focus on Social Cognition and is currently a PhD student at the Department of Differential Psychology at the University DuisburgEssen and freelance coach and supervisor. Among coaching her main research interests are non-verbal communication, stress and personality disorders. Her PhD topic focuses on the relationship between narcissim and empathy.

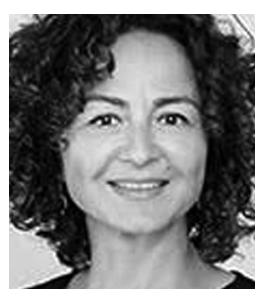

Melek Usta is the initiator and driving force behind Peer2Peer. Melek has been involved in education in various roles since 2000 as a supervisor, trainer, coach and consultant. Melek and her team have developed the Peer Support concept, of which she was co-initiator. Under the new Peer2Peer label, Melek and her team assist education and promote pupils social talents via special trainings and interventions. 